\title{
AVALIAÇÃO ULTRA-SONOGRÁFICA DE ALTERAÇÃO NO TAMANHO DA GLÂNDULA ADRENAL EM FERRET (Mustela furo) - RELATO DE CASO.
}

ALESSANDRA QUAGGIO AUGUSTO ${ }^{1}$; FABIANO MONTIANI FERREIRA ${ }^{2}$; RAFAEL CARTELLI $^{3}$

${ }^{1}$ Mestranda do Curso de Pós-Graduação em Ciências Veterinárias da Universidade Federal do Paraná; Vettech - Serviço Autônomo na Área de Ultra-sonografia Animal; Professora auxiliar da disciplina de Diagnóstico por Imagem do Curso de Medicina Veterinária da Pontifícia Universidade Católica do Paraná-PUC - Campus 2 (São José dos Pinhais) e da UNIPAR Umuarama. ${ }^{2}$ Professor Assistente da Disciplina de Clínica Médica de Pequenos Animais do Curso de Medicina Veterinária da Universidade Federal do Paraná. ${ }^{3}$ Mestrando na área de Patologia Animal do Curso de Pós Graduação em Ciências

Veterinárias da Universidade Federal do Paraná; Veterinário Encarregado pelo AMASOV (Ambulatório de Medicina de Animais Selvagens e Odontologia Veterinária do Hospital Veterinário - Universidade Federal do Paraná).

Um exemplar da espécie Mustela furo do sexo masculino, castrado, aproximadamente de dois anos de idade foi encaminhado ao AMASOV (Ambulatório de Medicina de Animais Selvagens do Hospital Veterinário - UFPR) apresentando apatia, desidratação, emagrecimento, disúria, alopecia na região caudodorsal, ventral e prurido. Após o exame físico foi realizada ultra-sonografia e colheita de sangue para dosagem de estradiol e cistocentese para urinálise. $\mathrm{O}$ exame ultra-sonográfico revelou um aumento da próstata com inúmeras áreas císticas de conteúdo denso, grande quantidade de restos celulares na bexiga urinária, rim direito com um cisto medindo aproximadamente $0,3 \mathrm{~cm}$ de diâmetro, rim esquerdo com um cisto medindo aproximadamente $1,5 \mathrm{~cm}$ de diâmetro, esplenomegalia, figado apresentando parênquima homogêneo com uma área policística medindo aproximadamente $2 \mathrm{~cm}$ de diâmetro e ambas adrenais medindo $0,9 \mathrm{~cm}$ de espessura. As alterações observadas no exame sugeriram aumento de volume da glândula adrenal A dosagem de estradiol revelou 132,64 pmol/L e urinálise revelou presença de bacilos gram negativos em grande quantidade e 3 cruzes de leucócitos e de hemácias. O paciente foi tratado com enrofloxaxina e com cetoconazole, atingindo uma melhora clínica durante o período de 11 meses. Os exames ultra-sonográficos eram realizados a cada 3 a 4 meses e as alterações mantinham-se constantes. Após este período de quase um ano o paciente apresentou recorrência dos sinais clínicos observados na primeira consulta. $\mathrm{O}$ paciente foi a óbito e encaminhado para a necropsia, onde foram observadas as mesmas alterações reveladas no exame ultra-sonográfico. Esta espécie animal apresenta uma grande percentagem de doenças hormonais, principalmente neoplasias como insulinomas e adenocarcinoma da glândula adrenal. Os sinais clínicos apresentados por este paciente e os resultados da ultra-sonografia e dos exames laboratoriais sugerem alteração na glândula adrenal do tipo hiperplasia ou neoplasia. Foi realizada dosagem de estradiol pois, a dosagem de ACTH não é confiável para esta espécie de animal. O exame ultra-sonográfico é uma técnica diagnostica não invasiva que possibilita a avaliação da arquitetura internas dos órgãos. Os sinais físicos e as imagens císticas encontradas em vários órgãos desta espécie animal estão relacionadas com alteração da glândula adrenal. 